\title{
Museus e linguagem: uma análise semiótica das interações entre museus e cidades
}

\author{
Museums and language: a semiotic analysis of the interactions \\ between museums and cities
}

Giulia Crippa

Universidade de São Paulo, campus de Ribeirão Preto, SP, Brasil

\begin{abstract}
Resumo: O artigo propõe uma base metodológica para o estudo dos museus enquanto objetos semióticos. Após uma introdução de caráter teórico-metodológico, o trabalho propõe uma leitura do Museu Judaico de Berlim como texto que se coloca, em sua arquitetura, em diálogo direto com seu ambiente histórico e topográfico, através de uma linguagem ligada à ausência, ao vazio, à dialética do dito e do silenciado. Em um segundo momento, examina a constituição de um museu que constrói a narrativa de seus objetos através da ficção, o Museu da Inocência, ilustrando as possibilidades de instituir uma memória coletiva dos indivíduos dentro da recuperação da memória de Istambul em um momento histórico particular, o do processo de modernização turco na década de 70. Em ambos os casos, o museu se apresenta como texto complexo cujas camadas podem ser analisadas.
\end{abstract}

Palavras-chave: Semiótica. Museu Judaico. Museu da Inocência. Memória. Cidade.

Abstract: The article considers a methodological base for the study of museums as semiotic objects. After a theoretical and methodological introduction, the work proposes a reading of the Jewish Museum of Berlin as a text that places itself, in its architecture, in a direct dialogue with its historical and topographical environment, through a language linked to absence and emptiness, with the dialectic of what is said and what is silenced. In a second moment, it examines the constitution of a museum that constructs the narrative of its objects through the fiction, the Museum of Innocence, illustrating the possibilities to institute a collective memory of the individuals, through the recovery of the memory of Istambul at particularly historical moment, that of the Turkish process of modernization in the decade of 70 . In both the analyzed cases, the museum presents itself as a complex text whose layers can be analyzed.

Keywords: Semiotics. Jewish Museum. Museum of the Innocence. Memory. City. 


\section{Introdução: museus e semiótica}

Em 1946, um ano depois do encerramento da guerra, o conhecimento norte-americano sobre a União Soviética era sobrecarregado pela propaganda anticomunista da Guerra Fria. Acreditava-se que os comunistas de Stalin se alimentavam de criança, que estavam prontos para invadir os Estados Unidos e que a população só padecia em um território visto - pelos olhos norte-americanos - como uma única, imensa estepe siberiana.

Na verdade, a população da União Soviética se encontrava na sua fase de reconstrução pós-bélica, enfrentando suas perspectivas de reconstrução e de volta a uma vida de paz. É esta, a conclusão à qual parece chegar Steinbeck e Capa em seu Um diário russo (2003), relato da viagem que o futuro Nobel realiza, com Robert Capa como companhei134 ro, exatamente em 1946, pela União Soviética. Estava em busca, diz ele em sua introdução, de uma comprovação das imagens e discursos sobre os novos inimigos.

A União Soviética que Steinbeck e Capa encontram é um país que fervilha com o entusiasmo de quem ganhou a guerra, pagando um preço altíssimo, e quer se reconstruir. Steinbeck e Capa visitam, entre outras, a cidade de Stalingrad e encontram um lugar muito particular. Entre julho de 1942 e fevereiro de 1943, Stalingrad fora bombardeada repetidas vezes, em uma das mais sangrentas batalhas da guerra. A cidade resistira, obrigando o inimigo a sofrer com ela os rigores do inverno. Ao término da batalha, mais de 2 milhões de pessoas, entre civis e soldados, tinham morrido. Com essa vitória soviética, as armadas alemãs começaram a recuar do front oriental.

Quando os dois viajantes americanos chegam, Stalingrad ainda está nas condições deixadas pela sua longa batalha. Durante a noite, é uma cidade fantasma, mas, com as primeiras luzes do dia, se anima com seus moradores, refugiados de suas próprias ruínas. Com surpresa, Steinbeck observa o entusiasmo compartilhado pela população, que se sente protagonista da história e não quer que isso seja esquecido. Assim, se nas ruas o autor percebe isso no cotidiano das pessoas, no encontro com o prefeito, aprende mais sobre os projetos de reconstrução da cidade. $\mathrm{O}$ orgulho maior do prefeito é o projeto final que deve coroar todos esses esforços de reconstrução, um projeto do qual ele fala com um entusiasmo absoluto, que evidentemente considera a chave de ouro de todo esse planejamento, realização cujo alicerce é o sacrifício de civis e militares: o Museu de Stalingrad, uma maquete que mostra aos dois 
americanos em visita. Trata-se de um projeto arquitetônico destinado a ocupar um lugar específico e de destaque na cidade futura, nas formas e no conteúdo do qual se materialize a memória da cidade. Steinbeck não é fascinado pelo museu em si, pois desde que chegou, com efeito, já foi "obrigado" a visitar vários museus, pelos quais, a certa altura, revela um certo tédio. Steinbeck fica encantado com a construção do discurso do prefeito, que "narra" o museu em seus mínimos detalhes, não como uma projeção futura, mas como algo que já existe "fora" do projeto. A maquete, para o prefeito de Stalingrad, já é o museu.

Interessa-nos essa passagem do diário russo porque introduz a ideia de museu não somente através da construção da narrativa do museu operada pelos semióforos, mas pelo fato de o próprio museu se tornar objeto de narrativa de memória. O museu é entendido como ma-

Museus e linguagem quete, reprodução fiel de um projeto de "embalagem" da memória, e, ao mesmo tempo, modelo e registro de um lugar pensado em relação ao território e à população com os quais deve dialogar em um específico território, inserido em uma urbanística significativa na construção da dialética com o museu.

O museu que dialoga com o espaço em que se insere, seja este um bairro, uma cidade, seja um espaço simbólico, tem se tornado um tema muito abordado pela literatura que discute significados e funções dos museus em todas as instâncias, desde sua ontologia até as tarefas executivas nele realizadas, passando pelas suas funções sociais, históricas, políticas e econômicas.

As linguagens do museu podem ser observadas por uma instância semiótica configurada na medida em que é ferramenta de interpretação de culturas e de modalidade de suas articulações, através de textos, discursos e artefatos significantes, interações, situações e formas de vida estudados através de modelos gerais que revelam diferenças gerais e específicas. 0 museu, organismo constituído, basicamente, por elementos heterogêneos de discurso, de natureza arquitetônica/urbanística, textual, iconográfica e, hoje, multimedial, enquanto objeto cultural, é objeto de interesse semiótico.

Para Lotman (1985), o museu é um exemplo de heterogeneidade vital e constitutiva da cultura, é forma que organiza e no qual se estratificam concreções de sentido diversas, significadas pela arquitetura, obras, objetos, suportes, sinalização, textos explicativos, posturas de curadores, funcionários e visitantes. Assim, expressões de subjetivida- 
des autônomas, neste espaço, entram em contato, em relação, em tradução, em conflito e em coexistência, originando um sistema dinâmico.

Neste artigo, analisaremos o museu como semioesfera, isto é: se, biologicamente, o homem precisa do ambiente apropriado do qual é parte integrante, a semioesfera organiza um processo análogo, mas no plano cultural. Toda semioesfera em que se articula o espaço global da semiose se caracteriza por dois elementos: necessidade de delimitação e irregularidade estrutural. Nesse sentido, Lotman considera o museu como semioesfera específica, sempre limitada em relação ao espaço em volta, que representa e, ao mesmo tempo, pertence a outra esfera semiótica: apresenta-se como homogênea, individual, dotada de personalidade semiótica. O conceito-chave para Lotman é o de fronteira: porosa, permeável, ela se torna lugar de tradução - "a fronteira semiótica é a soma dos 'filtros' semióticos de tradução. Atravessando-a o texto é traduzido em outras línguas externas à dada semioesfera" (LOTMAN, 1985, p. 59). Se a função da fronteira é de limitar a penetração e filtrar o externo para o interior, no caso de um espaço cultural com caráter territorial, este filtro adquire sentido espacial.

Em uma semioesfera, a cultura precisa de formas de autodescrição e, no processo de globalização, o museu se oferece como forma deputada para essa tarefa: é um espaço organizado estrategicamente que manifesta valores que caracterizam o universo semântico de uma sociedade, ou de parte dela, ou de alguma de suas especificidades. Lugar de dizeres enquanto dispositivo de produção de verdade, extensão, determinação e alteração de significados, objeto espacial de valor simbólico indiscutível no tecido urbano, mas, também, templo do capitalismo tardio: o museu ainda ocupa uma posição privilegiada tanto na apresentação e comunicação de seus conteúdos como na produção e colocação crítica de novos semióforos.

Desde meados do século XVIII, isto é, desde sua configuração como instituição pública, podemos considerar o museu como heterotopia, ou seja, como alteridade espacial, temporal e relacional: é um espaço especial, enquanto ambiente semiótico "outro" em relação ao cotidiano. Entrar em um museu e visitá-lo é ultrapassar um limite espacial que medeia e instaura contato com outros espaços/temporalidades/percepções do real. Heterotopias, segundo Foucault (1994), são espaços que possuem a característica peculiar de serem conectados com outros, de maneira a suspender, neutralizar ou inverter o conjunto de relações que estes desenham, refletem ou espelham. $O$ autor falava de instituições disciplinares, 
e, nesse sentido, o uso da palavra pode se ampliar para entender a relação entre a forma de organização do espaço e aquela social ou do saber. Semioticamente, ela pode espaçar entre a forma de expressão e a forma do conteúdo. $O$ espaço da prisão, por exemplo, revela a concepção de justiça e de pena de uma determinada sociedade, enquanto uma biblioteca apresenta as suas ideias de classificação e de acesso ao conhecimento. Trata-se, assim, de espaços codificados por caracteres distributivos detalhados, que podem ser funcionais, arquitetônicos, hierárquicos, mas, sempre para o autor, fundamentados no quadrillage, que imita o espaço do campo militar através do qual o controle do indivíduo se realiza, isolando

Museus e linguagem heterotopia é, então, a forma determinada por essa arte de divisão do espaço, em termos de isolamento e descontinuidade em relação ao cotidiano e de articulação em séries que definem, para cada indivíduo ou entidade, um espaço de pertencimento. As relações disciplinares acontecem também em edificações dedicadas à organização do saber, como é o caso dos museus (HOOPER-GREENHILL, 2003).

Colocadas, assim, as bases para a polifonia de textos da semioesfera museu, podem ser observadas as modalidades através das quais comunidades/culturas (ou partes delas) pensam e tratam seus signos, costurando a relação entre signos e realidade. 0 museu, portanto, como lugar/espaço onde o sentido é produzido pela confluência e o entrelaçamento de linguagens distintas que colaboram em função de uma semiótica sincrética, produz expressões particulares moduladas para produzir efeitos de sentidos unitários e globais

\section{A fronteira porosa da memória na arquitetura do $\mathrm{Mu}-$ seu Judaico de Berlim}

No espaço em que se encontra, o museu adquire uma individualidade que traduz sua cultura: para além de sua função de memória monumental, sua forma é congruente ou contraposta ao rosto da cidade, enfatizando suas características de fronteira.

Teóricos como Castells (2004) afirmam que à arquitetura deve ser confiada a tarefa de trazer de volta o sentido cultural do espaço como forma de vida e de deslocamento da atenção das intervenções sobre o espaço físico para aquelas no chamado "espaço dos fluxos", materiais e imateriais que caracterizam nosso tempo, fluxos de trabalhadores/ 
pessoas que se deslocam de um polo de interesse para outro/de mercadorias e, principalmente, de informações e comunicação.

O museu globalizado se revela, em primeiro lugar, pelas intervenções no perfil arquitetônico que, com frequência, o transforma em ícone metropolitano, fornecendo identidade a lugares que não a possuíam e tornando-se referência para fluxos de turistas na sociedade global.

Para esta discussão, tomaremos um exemplo berlinense, o Museu Judaico, projetado e edificado por Daniel Libeskind, por apresentar características de forte "porosidade" de suas fronteiras semióticas e pelo elemento do "vazio", constitutivo de sua linguagem arquitetônica.

O mundo inteiro observou o processo de reconstrução de Berlim após a queda do Muro. A cidade se tornou um grande canteiro de obras, uma cidade em que a experimentação urbanística e a arquitetônica encontraram um terreno fértil. Todavia, os fantasmas do nazismo e do comunismo estão presentes quando das filiações artísticas e arquitetônicas das intervenções urbanas.

Historicamente, Berlim encontra sua linguagem arquitetônica no século XIX e seu representante maior em Schinkel, pintor, escultor e, principalmente, arquiteto (FALLETTI; MAGGI, 2012). Ao mesmo tempo em que suas obras remetem às linhas inspiradas pelo classicismo, é também um representante significativo daqueles sonhos neogóticos e nibelúngicos que se colocam como base por um certo ecletismo. Descende de Schinkel a linha reta das edificações de Speer, o grande arquiteto do regime hitleriano (GAY, 2009), em prédios que sobreviveram aos bombardeios aliados e que, hoje, são sedes de importantes instituições.

Schinkel foi o artífice da chamada "Ilha dos Museus", onde se concentravam as principais coleções berlinenses do século XIX. Esta área, marcada por prédios em forma de majestosos templos, compreende o Pérgamon, exemplo interessante de narrativa museológica. Entre 1878 e 1886, durante sua aventura colonial, os alemães se depararam com um dos mais importantes achados arqueológicos: os restos integrais de um altar da cidade de Pérgamo, atualmente na Turquia. $O$ altar foi levado para Berlim, para ser reconstruído no interior de um prédio especificamente projetado para acolhê-lo. O museu, realizado entre 1910 e 1930, encontra sua narrativa mais excelente na década de 30, oferecendo uma visão épica do antigo que, sem solução de continuidade, do gigantesco altar, se entrelaça com a estrutura schinkeliana do museu, encontrando sua realização na República de Weimar. A retórica 
de seu arranjo, porém, já antecipa a retórica nazista, em sua disposição das civilizações representadas em volta dos muros babilônicos.

A arte da qual o nazismo procurou o aniquilamento foi o expressionismo. Antagonista por definição, louco pela linha transversal, desequilibrada e antissimétrica, o expressionismo desenvolve essa geometria particularmente no cinema. Em 1933, com a famosa exposição de Arte Degenerada, o expressionismo se torna indesejado, e, pouco tempo depois, a música segue o mesmo destino, obrigando os compositores a emigrar (constituindo um importante núcleo de artistas ligados a Hollywood), enquanto muitos músicos encontraram seu

Museus e linguagem fórmulas clássicas do legado schinkeliano, enquanto, do outro, procura revisitar as linguagens ligadas ao expressionismo.

Ainda na década de 80, um concurso internacional para a reconstrução de bairros inteiros, conhecido como IBA, reuniu os maiores e mais importantes estudos de arquitetura do mundo, culminando com a reforma urbanística confiada a Renzo Piano para Potsdamer Platz, até então a ferida mais evidente provocada pela divisão entre Leste e Oeste (MOLFINO, 2004).

O modelo espacial dominante da Era da Informação, como observado por Castells, dos museus, dos centros de convenções e dos nós de transporte, "lugares do imaginário cultural e de comunicação funcional, transformados pela arquitetura em formas de expressão cultural e compartilhamento de significados" (CASTELLS, 2004, p. 74), encontra sua realização com a proposta de um novo "centro" onde lojas, teatros, restaurantes e cafés permitem novas formas de sociabilidade.

Temos, então, um "pano de fundo" urbano com o qual tecer um diálogo: estilos arquitetônicos e vanguardas artísticas que, nos últimos dois séculos, materializam ideias e ideais. Tudo isso em uma cidade que se depara com a memória material de seu passado nazista e de divisão, com a qual deve contar para instituir suas identidades sociais, urbanas, políticas.

Neste pano de fundo, podemos agora colocar o Museu Judaico de Berlim, o ator principal desta discussão, que se institui como Memorial da história e do território com que dialoga principalmente nas suas formas arquitetônicas, fronteira entre memória museal propriamente dita e cidade, território em mutação. 
Resultado da aprovação no IBA, o projeto de Daniel Libeskind encontra sua realização na ampliação das ruínas de um prédio administrativo de 1735. 0 antigo prédio, destruído pelos bombardeios, foi reconstruído na década de 60 , mantendo as características e os detalhes clássicos, para hospedar o museu de Berlim. 0 projeto de Libeskind não apresenta nenhum ponto de contato externo com o prédio antigo, ainda que se trate de uma sua expansão. Não somente os dois prédios são separados externamente, mas a nova estrutura é emblemática, de arquitetura feita de linhas "expressionistas", em clara oposição com o antigo prédio, de concepção profundamente clássica. A obra de Libeskind é constituída por um único corpo "retorcido" por ângulos agudos que torna irregular o perfil do prédio, que, revestido por listas de metal e alto mais de seis andares, incumbe sobre os pedestres gigantesca estrela de David desestruturada, que, em sua "abertura", invade o território. A estrutura do revestimento em metal é "arranhada" por linhas entrecruzadas, de aparência irregular, onde se encaixam as janelas. Não se trata de linhas casuais, mas da reprodução do mapa daquela rua de Berlim onde havia moradores e trabalhadores judeus, reforçando essa presença judaica na história da cidade. Percebemos que já é o segundo "encontro" com uma ausência, com um vazio, com o que desapareceu e do qual o museu, já em sua arquitetura, se torna garantia da memória. O primeiro sinal de "ausência" é o elo invisível que une os dois prédios que constituem o museu. $\mathrm{O}$ antigo prédio, clássico, já museu da cidade, não revela sua relação com a cultura e a história dos judeus berlinenses, mas essa relação não somente existe. $O$ elo subterrâneo não é somente um lembrete da tentativa de aniquilação dessa história, é também "ponte" que, das "profundezas", constrói um diálogo com a nova estrutura. O segundo sinal de vazio é o próprio mapa gravado nas paredes, marcando os lugares de uma cidade que não existe mais, a não ser na memória registrada nos altos muros fechados. $\mathrm{O}$ exterior do museu, assim, se caracteriza por uma forte porosidade com o território circunstante. Aparentemente, o museu de Libeskind é uma estrutura sem acesso, sem diálogo: não tem uma entrada, não se vê sua ligação com o passado do prédio antigo, é alto e impérvio, escuro. Todavia, a estrutura inteira é voltada para sua presença capilar na cidade: a estrela de David que se "abre", invadindo desordenadamente os arredores, a topografia que sinaliza a presença, a interação de um mundo desaparecido com a cidade. 
Outros dois elementos "externos" aparentam ladear, sem contato visível, o prédio moderno. Trata-se de um alto caixote em concreto, com quatro lados irregulares, e de uma plataforma, sempre em concreto, com 49 altos pilares, sempre em concreto, oblíquos em relação à plataforma, cujos topos revelam a presença de uma oliveira em cada um.

A irregularidade da linha quebrada e transversal "invade" o hall de entrada, localizado no prédio antigo: trata-se do acesso a uma longa escadaria que leva para baixo, para os "porões", contrariando toda a tradição dos museus, que se "elevam" acima do nível das ruas, com suas altas escadarias. Aqui, o movimento é contrário, a visitação, para começar, desce aos infernos. $O$ elo entre os dois prédios é aqui subterrâneo,

Museus e linguagem das arquiteturas do gabinete do doutor Caligaris. Aos pés da escadaria, o visitante se encontra em uma encruzilhada, em que deve optar entre um dos dois eixos de visitação, o Eixo do Exílio ou o Eixo do Holocausto. $O$ ambiente subterrâneo, iluminado por longos neons que indicam os dois caminhos, começa a revelar nichos nas paredes, onde encontramos os primeiros semióforos. 0 eixo do exílio nos mostra cartas, malas, instrumentos musicais, roupas e objetos dos judeus berlinenses que escolheram o exílio, famílias e indivíduos que deixaram para trás vidas estáveis, amigos, parentes, trabalhos e escolas, procurando sua salvação alhures. A chegada deste movimento diaspórico é traduzida pela linguagem da arquitetura em uma plataforma externa, que se alcança sempre de maneira subterrânea. É o chamado "Jardim do Exílio". Após a viagem subterrânea, seguindo a memória dos semióforos, uma tranquilidade aparente nos cerca. A sensação de descanso é, porém, de breve duração, na medida em que os pilares oblíquos de concreto, no topo dos quais se encontram oliveiras importadas de Israel, provocam uma forte sensação de instabilidade e de mal-estar. Em breve, o visitante retomará sua andança, dessa vez ao longo do Eixo do Holocausto. Os objetos dos nichos nas paredes são da mesma categoria dos que já vimos no outro eixo (malas, roupas, objetos cotidianos), somente, dessa vez, não há nem a possibilidade de salvação, proporcionada pela instabilidade que sente o exilado. No final do eixo, um portão pesado, de metal, se abre sobre a escuridão de uma sala fria, de concreto, cuja acústica intensifica os ruídos externos da cidade. $O$ pesado portão se fecha com um som metálico, e o silêncio humano é quebrado unicamente pelos sons urbanos indistintos que provêm do exterior. 
Somente depois dessa descida aos infernos o visitante pode subir, através de uma longa escadaria que leva diretamente ao sexto andar, onde se encontra o espaço expositivo mais consistente, organizado para contar a história de 2 mil anos de convivência entre judeus e alemães.

A poética arquitetônica do museu se transforma, assim, em uma poderosa linguagem da memória que, atravessando os subterrâneos da cidade, (e)leva-nos entre as linhas-mapa que, como grafismos gigantescos, colocam-nos como transeuntes entre as ausências que elas delimitam.

O efeito sensorial do museu é poderoso. A visitação leva a deparar com partes do museu inacessíveis, isoladas, visíveis somente pelas janelas. Sua estrutura compreende corredores que terminam em cantos cegos, que não podem ser utilizados nem como espaços expositivos. Expõe-se a impossibilidade de expor, isto é, de dizer: a ausência e o invisível, as memórias desses pontos "sem texto". É evidente que, em um caso como este do Museu Judaico de Berlim, a necessidade de "expor" se torna secundária, pois o forte envolvimento emocional provocado pela linguagem do seu espaço permite ao visitante a apropriação da memória da segregação racial e da perseguição judaica. Com efeito, quando o museu foi inaugurado, em 2001, sem possuir coleções recebeu mais de 1 milhão de visitantes. Somente em momento posterior foi montada a exposição permanente de natureza histórico-didática sobre os 2 mil anos de convivência judaica na cidade e na Alemanha. Resta reforçar que a extraordinária arquitetura respondia, na elaboração de seus vazios, à necessidade de comunicar, exterior e interiormente, uma mensagem clara unicamente através de sua linguagem formal, tornando-se altamente simbólica não somente em relação à história do povo judeu, mas em seu compartilhamento sensorial com todos os habitantes e em seu espelhamento topográfico com o próprio tecido urbano em volta.

\section{Literatura: cidade e museu na "Inocência dos objetos" do Museu da Inocência}

No museu são recolhidos, organizados e expostos os semióforos (POMIAN, 1978), objetos/textos portadores de significado que, isolados do valor de uso, se tornam "signos de si mesmos" e do conjunto cultural do qual são parte. Na medida em que um gesto qualquer - mesmo o mais humilde, de deslocar um objeto, para restaurá-lo/preservá-lo/etiquetá-lo, contém uma comunicação - emite uma mensagem para o público, o gesto do museólogo nunca é neutro. A consciência de poder, deslocan- 
do até um único objeto, mudar/perturbar o equilíbrio de uma possível obra de arte, de um documento histórico que é o próprio museu, deve sempre ser submetida a toda operação museológica e museográfica.

Em seu A misteriosa chama da rainha Loana (2004), Umberto Eco narra situações em que imagens são associadas a conteúdos e em que, por sua vez, os conteúdos de cada imagem se entrelaçam. O protagonista do romance, Giambattista Bodoni, após um acidente perde sua memória biográfica. Para relembrar os acontecimentos de sua vida pessoal, se transfere para a casa de campo onde já morara quando criança. É nessa grande casa que estão reunidos materiais de natureza diferente, guardados em seus cômodos. Trata-se de selos, livros de aventura, gibis, jornais, discos, revistas e cadernos de escola do protagonista. Bodoni reúne, aos poucos, esses materiais, que desenrolam um verdadeiro arquivo-museu,

Museus e linguagem ao mesmo tempo individual e coletivo, enquanto repertório representativo da cultura da geração nascida logo antes da Segunda Guerra Mundial, durante o fascismo. A casa é um lugar que, em função da amnésia do protagonista, tornara-se labirinto, em que Bodoni se desloca como um explorador, como se estivesse desenrolando seu fio de Ariadne, que os leitores compartilham. Depois de reunir os materiais recuperados nos vários cômodos, Bodoni seleciona aqueles que acredita mais importantes para sua análise, organizando-os no escritório que fora do avô.

Inicialmente labiríntica e desconhecida para a personagem, a antiga casa torna-se, aos poucos, um museu, um lugar de memória em cada cômodo, no qual Bodoni e os leitores entram em contato com as imagens, objetivadas em seus diversos suportes, que, despertando aos poucos uma exposição considerada significativa de semióforos de uma época, (re)constitui a memória do protagonista.

Em 2009, o Museu do Louvre encomendou a curadoria de uma exposição a Umberto Eco, que esboçou uma ampla reflexão sobre o tema da seleção e organização de listas de palavras, objetos e conceitos com novos limites, derivas e excessos, construída como metalista aberta, em seguida reunida em seu livro Vertigine della lista (2009). Tanto no romance A misteriosa chama da rainha Loana como em sua exposição, a coleção de listas textuais, visuais, sonoras e arquitetônicas se torna proposta de museus possíveis que (des)ordenam e reformulam, virtualmente ou em realidades locais, o patrimônio existente (como aconteceu no Louvre). Neste caso, a arquitetura e sua organização conceitual passam em segundo plano, em uma análise semiótica em relação ao critério de re- 
organização dos semióforos, que se sobressai, neutralizando-as, discutindo-as e ressemantizando-as.

A literatura, então, participa efetivamente das Artes da Memória. Não somente porque há textos literários que incluem visitas a museus ou galerias, mas porque se propõem eles mesmos como museus cujos semióforos são as palavras que constituem listas e inventários de objetos significantes. A linguagem, lugar de práticas expositivas, garante a conservação, retira, para essa finalidade, os topoi da linguagem da arquitetura; e Mnemosyne, musa da memória e mãe das artes, utiliza os lugares da retórica para compor seus textos.

A forte descontinuidade entre as diversas formas de inscrição textual e material da vida como objeto de memória, entre literatura 144 e as inscrições da memória nos lugares estratificados de uma cidade, é o que constitui a matéria da narrativa de um produto literário, de autoria do Prêmio Nobel de 2006, o turco Orhan Pamuk, que, em 2012, inaugurou um pequeno museu em Istambul, chamado Museu da Inocência. Substancialmente, o escritor realiza, materialmente, o projeto de museu narrado por Eco. Em primeiro lugar, o autor investiga, vasculha a memória de Istambul em um dúplice movimento de busca dos "lugares" de memória na cidade e nos textos que a representam e de comparação de suas memórias autobiográficas do nascimento até o começo de seus estudos universitários. Trata-se de um relato que se desenvolve em volta da definição de hüzün, tristeza em turco. Trata-se do topos que sustenta a própria criação do museu, portanto importa buscar essa definição no próprio autor, que a constrói no décimo capítulo de Istambul (PAMUK, 2008). Em sua coleção de lugares e textos, o autor parece se deparar com a necessidade de se confrontar com este sentimento de tristeza que identifica com o sentimento da perda. Pamuk se confronta com as perdas individuais mas, principalmente, com a experiência coletiva da cidade de Istambul com a hüzün. Ainda que a origem da palavra seja árabe e no Alcorão existam duas visões sobre a tristeza, uma negativa porque demonstra um excessivo interesse para as coisas materiais, e uma positiva, a da tristeza consciente pela distância do divino, para Pamuk a palavra envolve Istambul além da visão mística. É a perda que se enraíza no desaparecimento de um grande império e de suas consequências, entre as quais, trilha que o escritor escolhe para si, as paisagens urbanas que desaparecem. Nesta perda reside, para Pamuk, a tristeza da cidade. 
Todavia, Pamuk não se refere às grandes paisagens da potência imperial, mas àquelas do sonho da modernidade. Segundo Benjamin, a civilização burguesa que se desenvolve a partir da primeira metade do século XIX leva a um processo de expansão espetacular da participação das massas à vida pública, através de novas formas de comportamentos sociais e de uma nova organização urbana (BENJAMIN, 2007). A partir dessa época, aparecem os espaços do welfare e do consumo, até então inéditos. A revolução que caracteriza a cultura da cidade se expressa nas estruturas urbanas, através de parques, promenades, passagens, galerias, lojas de departamento, para chegar à expressão últiMuseus e ma das grandes exposições universais, oferecidas como momentos de comemoração da nova mitologia científico-tecnológica e patriótica da época. As exposições não somente celebram a inovação, mas também linguagem adquirem um papel central para o imaginário coletivo, em divulgar o espírito das máquinas e a sedução das mercadorias e sua mise-en-scéne como mitologias modernas de progresso, até sua configuração em formas expressivas da cultura de massa e da sociedade do espetáculo.

Assim, a palavra "exposição" se torna polissêmica, identificando-se com as formas organizacionais de valores, conteúdos, tamanhos, estruturas, ofertas e estilos de lazer, com os tempos de realização e as formas de abertura aos públicos diversos conforme os tempos da inovação e as geografias dos comércios e do volume dos produtos, com a quantidade e qualidade das informações, das memórias e das classificações, através das quais é representado o universo inteiro das ciências e das artes. Uma forte relação se estabelece entre texto literário, memória e exposição, que se consolida sobre o pano de fundo daquela entre cidade e literatura. Durante o século XIX, a metáfora cidade-livro se torna um tema privilegiado: enquanto a cidade é um "volume" a ser percorrido, a literatura adquire valor de viagem pela cidade. "Exposição" é, assim, a palavra que guia e catalisa esse entrelaçamento, que se apresenta em modalidades disfóricas, como perda de sentido e de valor, ou eufóricas, como dominação do mundo reduzido a lista ou catálogo, onde à desordem do excesso de objetos da realidade se opõe sua organização racional, como em uma loja de departamento (ECO, 2003).

Pamuk busca identificar esta paisagem pós-imperial, constituída por uma "lista", um "catálogo" de memórias: 
Giulia Crippa

146

Falo da escuridão do cair da noite que chega cedo, dos pais que voltam para casa debaixo da luzes dos bairros periféricos, com sacolas na mão. Falo dos velhos livreiros que, depois de alguma das frequentes crises econômicas, esperam o dia inteiro, arrepiados pelo frio, um leitor; dos barbeiros reclamando da queda de fregueses; dos marinheiros que lavam as velhas balsas do Bósforo, atracados aos antigos piers vazios, sobre os quais adormecerão em breve, e no entanto espiam uma pequena TV de longe, em preto e branco; das crianças que batem uma bola entre os carros nas vielas estreitas e ladrilhadas; das mulheres de cachecol na cabeça e as sacolas de plástico na mão, que esperam silenciosamente o ônibus nos pontos da periferia; dos galpões para os barcos das velhas yali; dos salões de chá lotados de desempregados; dos rufiões que, pacientes, rondavam as calçadas na esperança de encontrar um turista bêbado na maior praça da cidade; da multidão que, nas noites de inverno, corre para pegar a balsa a tempo; das mulheres que à noite, esperando por seus maridos, entreabrem as cortinas para espiar rapidamente [...]. (PAMUK, 2008, p. 92-94).

A lista continua com lugares, sensações, cheiros e cores ao longo de mais de três páginas, constituindo, basicamente, os verbetes da memória, da perda, que devem ser recuperados.

O segundo "movimento" para a constituição do museu é constituído por seu tecido narrativo. Não é Istambul que rege a estrutura de um museu real, mas um romance.

Em O museu da inocência (2009), o autor narra uma história de amor ambientada na Istambul da década de 70. O protagonista, Kemal Basmaci, é noivo da jovem Sibel, quando encontra a prima Fusun, pela qual se apaixona e com a qual tem um relacionamento breve, porém intenso. A história deles, todavia, acaba, pois Kemal não rompe com a noiva. Separados, Kemal se apercebe de que sem Fusun não consegue viver e passa oito anos em busca da possibilidade perdida dessa história de amor. Como "antídoto" à sua dor de amor, Kemal começa a recolher objetos que pertenceram a Fusun ou que remetem a lugares e momentos associados a ela. Ele guarda esses objetos no apartamento onde se encontrava com a moça. Quando Fusun morre, Kemal toma a decisão de comprar dos pais dela a casa onde morava e de expor os objetos recolhidos aos olhares do público, inaugurando, assim, o Museu da Inocência. 
Raramente um romance é tão fiel ao seu título: ler 0 museu da inocência é como entrar e visitar um museu. Virar as páginas corresponde a visitar suas salas, em que nos deparamos com os objetos expostos nas vitrines, lendo as legendas que constituem um verdadeiro catálogo raisonné. Assim como em um museu, o autor reconstrói um mundo, salvando-o do esquecimento. $\mathrm{O}$ autor nos devolve a história de amor entre Kemal e Fusun, em cada detalhe singular, e, ao mesmo tempo, recria a vida de uma cidade, Istambul, na década de 70.

As datas são importantes em qualquer museu: nesse, a primeira é 26 de abril de 1975 e a última será nove anos e quatro meses depois. A primeira é a data do dia em que Kemal entra na loja onde Fusun trabalha como vendedora, e a última é do dia em que Kemal e Fusun viajam para a Europa, quando tudo acaba. A simples história desse amor é, na

Museus e linguagem verdade, a desculpa para construir um lugar de memória através de objetos: verdadeiros protagonistas são esses "documentos materiais", e a história que adquire relevância é a de como se constitui uma coleção. Quando a noiva de Kemal o abandona, o protagonista reencontra Fusun, casada, e começa um louco período em que ele frequenta a casa dela e de sua família entre três e cinco vezes por dia. Ao longo de sete anos, dez meses e três dias, ao longo de 409 semanas, Kemal janta na casa da família da moça 1.593 vezes.

A exatidão dos números é importante, pois oferece uma medida da meticulosidade doentia com que Kemal conserva, em sua memória, os vestígios de seu amor. A essa altura da história, ele ainda não sabe que, depois de visitar 5.723 museus, dedicaria um museu a Fusun. Começa, todavia, a acumular objetos que pertenceram à moça, roubando na casa dela lenços, grampos, bibelôs, saleiros. Em seguida, amplia o campo de sua coleção, pois Fusun não é mais somente Fusun, tornou-se a cidade em que se amaram, está no navio do qual seus olhos se pousaram sobre o Bósforo, na garrafa de refrigerante, nos outdoors publicitários, na caixa de cigarros (ou na própria bituca), nos shows televisivos e em suas guias de programação, em uma infinidade de objetos e imagens que acabam se recompondo, como em um caleidoscópio, dentro do Museu da Inocência, espécie de Jardim do Éden antes da queda. Ainda que, aparentemente, no centro da memória se encontre Fusun, é, na verdade, Kemal que sempre fala de Kemal, personagem narcisista, frequentemente irritante, que encerra sua narrativa afirmando que teve uma vida feliz, sem se perguntar quantas pessoas, por causa disso, foram in- 
felizes, e que - com uma pirandeliana virada narrativa - pede ao escritor Orhan Pamuk (que já encontramos dançando com Fusun durante a festa de noivado de Kemal com Sibel) para escrever o livro que estamos lendo, para que esse desenvolva o papel de catálogo e guia completo do museu, para que todos os visitantes possam se deslocar por suas vitrines com a clareza do que estão vendo e das razões pelas quais os objetos estão ordenados conforme uma dada narrativa.

Há um inteiro capítulo dedicado aos museus que o protagonista descreve. Museus reais, museus existentes, de todos os tipos e natureza. Um inteiro catálogo de modelos que constituem o prisma através do qual reivindicar uma memória que se encontra entre o Ocidente e seus ideais de modernidade e o Oriente das memórias enraizadas nas tradições das relações sociais em uma Turquia cujo recorte de exposição é a dialética Oriente/Ocidente.

Em 1999, Orhan Pamuk comprou um palacete histórico em Istambul para realizar um projeto ligado ao romance, encarregando o arquiteto Ihsan Bilgin - antes de começar a escrever o romance - de transformar o prédio em um museu, onde o livro e o próprio museu se cruzassem na história de amor entre Kemal e Fusun, os protagonistas. Depois de nove anos, nasceu o romance e, em 2012, o Museu da Inocência foi inaugurado.

Nas últimas páginas do romance, Pamuk elabora de maneira clara e eficaz uma verdadeira "teoria do museu e das coleções", oferecendo, inclusive, um mapa para chegar facilmente às suas instalações e dependências e a cópia de um bilhete de uma entrada, que todo leitor poderá apresentar para visitar o museu: será um percurso lento, às vezes tedioso, às vezes dará vontade de pular alguma sala e deixar de lado alguma relíquia que nos parece já conhecida. No final, todavia, sairemos do museu com a sensação de ter visitado a vida, de que se trata de uma coleção de "momentos felizes".

O protagonista de 0 museu da inocência propõe novos sentidos à memória museológica, em contextos aparentemente canônicos, mas que, a bem ver, colocam em xeque as ideias da própria cultura ocidental, através de uma síntese entre, de um lado, formas de organização moldadas na tradição e, do outro, seleção de objetos ligados ao sentir memorialístico de outra cultura da modernização, baseada no desaparecimento de outra realidade, a do Império Otomano. 0 catálogo, no qual se encontram a lista de objetos, suas origens e seus percursos, ad- 
quire, aqui, forma plena de narrativa, sem abdicar de sua função de guia completo das obras.

O tema da perda da memória e de sua reconstituição através da coleção de objetos comuns de produção industrial e de consumo de massa aproxima de maneira evidente o romance de Eco e o Museu da Inocência.

Istambul pode ser visto como o documento que origina as demandas para a constituição de uma memória coletiva, de uma cidade, de um museu. Constituídas essas demandas, elas adquirem sua forma narrativa literária. $O$ romance é o catálogo literário, a chave para adentrar o lugar que institui a memória, a cidade da década de 70, povoado por personagens e objetos. A história de amor, que se desenrola através dos objetos, se torna, então, história da cidade, através da técnica (poderíamos dizer de catalogação literária) do autor: após relatar um episódio do amor de

Museus e linguagem Kemal e Fusun ligado a um objeto, ele se debruça sobre a chegada e a difusão daquele mesmo objeto na Turquia da época. É nessa dimensão que nos apercebemos, ao lado de Kemal, de que o trabalho de coleta e de resgate do esquecimento dos objetos e do que representam não é somente um ato de valor individual. $\mathrm{O}$ entrelaçamento entre a história de Kemal e a da cidade é dúplice e complexo: de um lado, a mentalidade contraditória e atrasada da burguesia urbana, em particular em relação à condição das mulheres, e, do outro, Fusun, frágil e destinada a desaparecer, nada mais é que a cidade de Istambul, submetida a transformações violentas, como os incêndios dos casarões do Bósforo ou seu abandono ao desinteresse geral, sem cuidados com sua identidade nem com seu passado.

A referência a uma abordagem antropológica do museu é explícita, quando comparada com o trabalho de Clifford (1993) e à sua ideia de museu como reconstituição de um lugar em um tempo, como unidade espaço-temporal de tamanho porte que permita a reflexão sobre sua própria existência. Muito distante, neste sentido, da ideia de museu como ambiente frio de objetos de valor patrimonial no sentido clássico do termo, as "grandes obras" do gênio e da ciência, e muito próximo do espaço do flaneur de Benjamin.

É, assim, um longo percurso aquele que leva Pamuk das fotografias em preto e branco da casa - museu escuro da família, descrito no segundo capítulo de Istambul - até o museu-casa dedicado a Fusun. Vivendo nos cômodos da burguesia turca, revestidos na superfície pelo desejo de ocidentalização, na época pensava que todos aqueles objetos "estivessem lá expostos não para a vida, mas para a morte” (PAMUK, 2008, p. 11). 


\section{Algumas considerações sobre a memória de amanhã}

À proliferação de objetos (ou mercadorias) corresponde, para Agamben (2005), uma perda inexorável e progressiva de qualquer uso possível que, exatamente no museu (não somente espaço físico, mas verdadeira "outra" dimensão), encontra sua expressão mais emblemática: “a impossibilidade de usar encontra seu lugar tópico no museu. A museificação do mundo é, hoje, um dado de fato" (AGAMBEN, 2005, p. 96). A interpretação sugerida por Agamben coloca o museu sob o signo da subtração, da separação, da perda de sentido que é indicativa de quanto o museu seja um lugar irrenunciável de reflexão e de oposições em uma época em que, apesar das polêmicas e das contestações, a presença de museus e de seus rituais está em constante expansão.

Nesse sentido, a civilização da informação e da comunicação escolhe, como referência para a sua memória, o museu. Porém, se a função "clássica" desse lugar era de preservar a memória através da exposição dos objetos, acolhendo o público com suas narrativas "heroicas" de grandes feitios e de desenvolvimento nacional, hoje há a busca de uma narrativa mais imbricada no território em que se insere, tanto no diálogo de sua "fronteira" como na dimensão antropológica de relato de vida de indivíduos.

Assim, o museu contemporâneo se desenvolve sem uma tipologia pré-fixada, em uma mestiçagem entre os elementos da arquitetura das bibliotecas, do espetáculo, do comércio e da residência. Torna-se um espaço público com as características de uma época em que a contemplação espiritual se une ao consumo, tornando-se lugar que, em seus códigos, revela essa contradição.

Os objetos escolhidos e organizados em coleções são dispostos em percursos significantes para os públicos por sujeitos (curadores, museólogos) delegados à função de pesquisa, seleção, preparo, valorização, construção de significado e comunicação. A realização de um museu se torna, assim, a de uma forma complexa produtora de traços enunciativos que se reconduzem a um projeto completo, articulado em vários níveis de pertinência.

Portanto, o museu é um espaço no qual o sentido é produzido pela confluência e o entrelaçamento de linguagens distintas, que colaboram em função de uma operação semiótica sincrética, em que as expressões particulares contribuem para produzir efeitos de sentido unitários e globais. 


\section{Referências}

AGAMBEN, G. Profanazioni. Roma: Nottetempo, 2005.

BENJAMIN, W. Immagini di città. Torino: Einaudi, 2007.

CASTELLS, M. La città delle reti. Veneza: Marsílio, 2004.

CLIFFORD, J. I frutti puri impazziscono: etnografia, letteratura e arte nel secolo XX. Torino: Bollati-Boringhieri, 1993.

Museus e

linguagem

ECO, U. Il museo nel terzo millennio. Bilbao, 2003. Disponível em: <http://www.umbertoeco.it>. Acesso em: 20 fev. 2013.

. La misteriosa fiamma della regina Loana. Milano: RCS, 2004.

Vertigine della lista. Milano: Bompiani, 2009.

FALLETTI, V.; MAGGI, M. I musei. Bologna: Il Mulino, 2012.

FOUCAULT, M. Eterotopia. In: Millepiani n. 2: Michel Foucault: eterotopia. Luoghi e non-luoghi metropolitani, Milano: Mimesis, 1994.

GAY, P. Modernismo: o fascínio da heresia. São Paulo: Companhia das Letras, 2009.

HOOPER-GREENHILL, E. Museum and the shaping of knowledge. London: Routledge, 2003.

LOTMAN, J. La semiosfera: l'asimmetria e il dialogo nelle strutture pensanti. Venezia: Marsílio, 1985.

MOLFINO, A. M. L'etica dei musei. Torino: Allemandi, 2004.

PAMUK, O. Il museo dell'innocenza. Torino: Einaudi, 2009. Istanbul. Torino: Einaudi, 2008. 
POMIAN, K. Collezione. In: Enciclopédia. Torino: Einaudi, 1978. v. 3.

STEINBECK, J.; CAPA, R. Um diário russo. São Paulo: Cosac Naify, 2003.

Giulia Crippa

152 